\title{
Classic Bartter syndrome
}

INSERM

\section{Source}

INSERM. (1999). Orphanet: an online rare disease and orphan drug data base. Classic

Bartter syndrome. ORPHA:93605

Classic Bartter syndrome is a type of Bartter syndrome (see this term), characterized by a milder clinical picture than the antenatal/infantile subtype, and presenting with failure to thrive, hypokalemic alkalosis, increased levels of plasma renin and aldosterone, low blood pressure and vascular resistance to angiotensin II. 